\title{
Assessment of the Photobiomodulation Effect of a Blue Diode Laser on the Proliferation and Migration of Cultured Human Gingival Fibroblast Cells: A Preliminary In Vitro Study
}

\author{
Ardavan Etemadi', Soheil Taghavi Namin², Mahshid Hodjat ${ }^{3}$, Emad Kosarieh ${ }^{4}$ Neda Hakimiha ${ }^{*}$ \\ ${ }^{1}$ Assistant professor, Department of periodontology, Faculty of Dentistry, Islamic Azad university, Tehran, Iran; Laser Research \\ Center of Dentistry, Dental Research Institute, Tehran University of Medical Sciences, Tehran, Iran \\ ${ }^{2}$ DDS, Private practice, Tehran, Iran \\ ${ }^{3} \mathrm{PhD}$, Assistant Professor, Dental Research Center, Dentistry Research Institute, Tehran University of Medical Sciences, \\ Tehran, Iran \\ ${ }^{4}$ DDS, MSc, Periodontist, Laser Research Center of Dentistry, Dental Research Institute, Tehran University of Medical \\ Sciences, Tehran, Iran \\ ${ }^{5} \mathrm{DDS}, \mathrm{PhD}$ candidate in laser dentistry, Laser Research Center of Dentistry, Dentistry Research Institute, Tehran University of \\ Medical Sciences, Tehran, Iran
}

\section{*Correspondence to \\ Neda Hakimiha, DDs, PhD candidate in laser dentistry, Laser Research Center of Dentistry, Dentistry Research Institute, Tehran University of Medical Sciences, Tehran, Iran. Postal address: Qods street, Enqelab Avenue, Tehran, Iran Postal code:1417614411; Tel: +982188384306 ; Email: \\ Ned.hakimiha@gmail.com}

Published online October 3 , 2020

\begin{abstract}
Introduction: Photobiomodulation therapy (PBM) is emerging as an effective strategy for the management of wound healing. The application of red and near infra-red light sources in laser therapy has been the subject of most researches in recent literature. Considering the lack of sufficient evidence in assessing the blue light in PBM, we aimed to investigate the photobiomodulation effect of a blue diode laser on the proliferation and migration of cultured human gingival fibroblast cells as a preliminary in vitro study.

Methods: Human gingival fibroblast cells were irradiated with a blue diode laser at a $445 \mathrm{~nm}$ wavelength. Irradiation was done using three different powers of $200 \mathrm{~mW}$ (irradiation times of 5, 10,15, and 20 seconds); $300 \mathrm{~mW}$ (irradiation times of 5, 10, and 15 seconds); and $400 \mathrm{~mW}$ (irradiation times of 5 and 10 seconds). The fibroblast cells without laser exposure were considered as control. After 24 hours of incubation, the MTT assay and the wound scratch test were performed on the cells to investigate the biomodulation effect of the blue laser on the proliferation and migration of the cells respectively. The results were analyzed by one-way ANOVA and a post-hoc Tukey test with a $P$ value $<0.05$ as a statistical significance level.

Results: PBM with blue diode laser at power densities of $400 \mathrm{~mW} / \mathrm{cm}^{2}$ with irradiation times of 10 and 15 seconds corresponding to energy densities of 4 and $6 \mathrm{~J} / \mathrm{cm}^{2}$ exerted the statistically significant positive effect on both proliferation and migration of gingival fibroblast cells.

Conclusion: Considering the encouraging findings of this study, PBM with blue diode laser can promote proliferation and migration of human gingival fibroblasts, the key cells involved in the process of oral wound healing.

Keywords: Fibroblasts; Low-level light therapy; Cell proliferation; Cell migration assays.
\end{abstract}

\section{Introduction}

A blue diode laser which emits light at $445 \mathrm{~nm}$ is one of the newest wavelengths marketed in the field of laser dentistry. This wavelength has the highest absorption in hemoglobin and melanin compared to the other diode lasers, which results in a better quality of cuts with a lower power setting and minimal thermal damage to the tissues. These features make blue lasers popular in dental surgery. ${ }^{1,2}$
Although the benefits of using a blue diode laser in cutting tissue are well-known, still not much is known regarding the effect of this wavelength at a low-power setting in the photobiomodulation manner. Photobiomodulation therapy (PBM), previously named low-level laser therapy, refers to the therapeutic use of light usually in the wavelengths ranging between $600-1100 \mathrm{~nm}$ at lowpower outputs. This treatment modality targets specific chromophores $^{3}$ predominantly cytochrome c oxidase,

Please cite this article as follows: Etemadi A, Taghavi Namin S, Hodjat M, Kosarieh E, Hakimiha N. Assessment of the photobiomodulation effect of a blue diode laser on the proliferation and migration of cultured human gingival fibroblast cells: a preliminary in vitro study. $J$ Lasers Med Sci. 2020;11(4):491-496. doi:10.34172/jlms.2020.77. 
light-sensitive ion channels, flavin, and flavoproteins ${ }^{4,5}$ to initiate several nonthermal and biological reactions. These events lead to physiological changes in favor of an increase in protein synthesis, cell migration and proliferation, and anti-inflammation signaling. ${ }^{6}$ PBM can promote tissue repair in the oral cavity by biostimulatory effects on different cell types, including gingival fibroblast cells. It can increase the migration and proliferation of the cells by inducing a stimulative effect on the expression of related growth factors leading to the repopulation of the damaged area. ${ }^{7}$

Cell proliferation is a critically important physiological sign of the positive effect of photobiomodulation in the process of wound healing. It is also closely associated with the cell migration ability. Indeed, fibroblasts play a vital role in the wound healing process due to their migration to the wound site and mediate lysis fibrin clot structure, synthesis of an extracellular matrix, and production of collagen leading to healing and contracting the wound. ${ }^{7,8}$ To the best of our knowledge, there is no study addressing the biostimulative effect of the $445 \mathrm{~nm}$ diode laser on the human gingival fibroblasts. Considering insufficient evidence in this research area, we aimed to evaluate the photobiomodulation effect of a blue diode laser on the proliferation and migration of cultured human gingival fibroblast as a preliminary in vitro study.

\section{Materials and Methods}

Cell Culture

Human gingival fibroblast cells were obtained from the Iranian Biological Resource Center, Tehran, Iran and cultured in DMEM (Dulbecco's modified Eagle's medium, Biosera, France) containing 10\% FBS (Gibco, USA), then incubated at $37^{\circ} \mathrm{C}$ in a humid environment containing $5 \%$ $\mathrm{CO}_{2}$. For the evaluation of the fibroblast proliferation and migration rate as the primary outcomes of the current study, the cells were seeded at a density of 10000 cells/well in a 96-well plate. To avoid light transmission between adjacent wells during laser radiation, each seeded well was surrounded with one empty neighboring well.

\section{Laser Irradiation}

In order to evaluate the biomodulation effect of single irradiation of a blue laser on the proliferation and migration of cultured human fibroblast cells, we considered different energy densities of the blue $445 \mathrm{~nm}$ diode laser (SIRO Laser Blue, Sirona Dental Systems $\mathrm{GmbH}$, Bensheim, Germany) in power ranges between 200-400 mW as listed in Table 1. One group without irradiation was considered as control. Irradiation in studied groups was done at a distance of $1 \mathrm{~mm}$ by a therapy handpiece with a beam diameter of $8 \mathrm{~mm}$ (spot size: $0.5 \mathrm{~cm}^{2}$ ) in a continuous mode of irradiation.

\section{Cell Proliferation (MTT Assay)}

Twenty-four hours after laser radiation, the cells were subjected to MTT (3-(4,5-dimethylthiazol-2-yl)-2,5 diphenyltetrazolium bromide) calorimetry assay to measure the cell survival and proliferation rate in response to laser irradiation. In the MTT procedure, tetrazolium salt is cleaved by mitochondrial dehydrogenases in living cells to form a purple-colored formazan crystal to yield an estimate of cellular viability and metabolic activity. Briefly, the culture supernatant was removed before the addition of $50 \mu \mathrm{L}$ of the $5 \mathrm{mg} / \mathrm{mL}$ MTT (Atocell, Austria) solution and incubated for about 2 to 4 hours at $37^{\circ} \mathrm{C}$ in dark. After incubation, the reaction was stopped by the addition of $200 \mu \mathrm{L}$ Dimethyl sulfoxide (Sigma, Germany) to dissolve the dye crystals. The absorbance was measured at $540 \mathrm{~nm}$ with a $650 \mathrm{~nm}$ reference wavelength using a microplate reader (Biotek Instruments, Inc.). ${ }^{9}$

\section{Cell Migration (Wound Healing Assay)}

The wound healing assay was done to evaluate the effect of laser irradiation on the migration of the fibroblast cells. This phase of the study was done based on MTT assay results. We selected the irradiation setting of three groups of lasers that had the highest scores on cell proliferation in MTT assay results (Table 2).

The next day after culturing the cells (before laser radiation) at a 96-well plate, the linear scratch was created

Table 1. Study Groups in the MTT Assay Test

\begin{tabular}{|c|c|c|c|c|c|c|}
\hline Group Number & Power(w) & Time(s) & Irradiation Mode & Power Density $\left(\mathrm{mW} / \mathrm{cm}^{2}\right)$ & Radiant Energy (J) & Energy Density $\left(\mathrm{J} / \mathrm{cm}^{2}\right)$ \\
\hline 0 & Without irradiation & - & & - & - & - \\
\hline 1 & 0.2 & 5 & Continuous & 400 & 1 & 2 \\
\hline 2 & 0.2 & 10 & Continuous & 400 & 2 & 4 \\
\hline 3 & 0.2 & 15 & Continuous & 400 & 3 & 6 \\
\hline 4 & 0.2 & 20 & Continuous & 400 & 4 & 8 \\
\hline 5 & 0.3 & 5 & Continuous & 600 & 1.5 & 3 \\
\hline 6 & 0.3 & 10 & Continuous & 600 & 3 & 6 \\
\hline 7 & 0.3 & 15 & Continuous & 600 & 4.5 & 9 \\
\hline 8 & 0.4 & 5 & Continuous & 800 & 2 & 4 \\
\hline 9 & 0.4 & 10 & Continuous & 800 & 4 & 8 \\
\hline
\end{tabular}


Table 2. Study Groups in Wound Healing Assay

\begin{tabular}{lcccccc}
\hline Group Number & Power $(\mathbf{w})$ & Time $(\mathbf{s})$ & Irradiation Mode & Power Density $\left(\mathbf{m W} / \mathbf{c m}^{2}\right)$ & Radiant Energy $(\mathbf{J})$ & Energy Density $\left(\mathbf{J} / \mathbf{c m}^{2}\right)$ \\
\hline 0 & Without irradiation & - & - & - & \\
2 & 0.2 & 10 & Continuous & 400 & 2 & 4 \\
3 & 0.2 & 15 & Continuous & 400 & 3 & 4 \\
9 & 0.4 & 10 & Continuous & 800 & 4 & 4 \\
\hline
\end{tabular}

by scratching the confluent monolayer of cells using a sterile pipette tip. Twenty minutes after scratching, the cells were exposed to a laser beam. Eighteen hours after the irradiation, the scratch wounded-cells were fixed with $2 \%$ paraformaldehyde (Merk, Darmstadt, German) in PBS for 10 minutes at room temperature and permeabilized with $0.1 \%$ Triton $\mathrm{X}-100$ for three 10 minutes, followed by DAPI staining (1:1000) for five 10 minutes. The cells were then washed two times with PBS and images were taken under a microscope (Olympus BX51, Japan). The area of the scratch wound was manually measured using imageanalysis J 1.45S software (Wayne Rasband, National Institutes of Health, Bethesda, MD, USA). ${ }^{10}$ The assay was performed in triplicate for each sample.

All the experiments including the cell culture, the MTT assay, and the cell migration test were carried out at a cellular and molecular laboratory in the dental research center, dentistry research institute, Tehran University of Medical Sciences.

\section{Statistical Analysis}

The data were analyzed by one-way ANOVA and the post-hoc Tukey test using IBM SPSS statistics 16 software (IBM Corp., Armonk, NY, USA). All experiments were repeated at least three times and all samples were analyzed in triplicate. The $P$ value $<0.05$ was defined as a statistical significance level.

\section{Results}

MTT Assay

The results of the MTT assay in the studied groups are illustrated in Figure 1. According to the viability percentage of the cells obtained from MTT assay, the irradiation of fibroblast with energy densities of 4 and $6 \mathrm{~J} / \mathrm{cm}^{2}$ with 200 $\mathrm{mW}$ power in groups 2 and 3 had a significant positive proliferative effect ( $P$ value $<0.001$ and 0.001 respectively) compared to the control non-irradiated cell group. The other laser groups had a positive although not statistically significant effect on the viability of the cells.

Wound Healing Assay

Based on the results of the MTT assay, the three best settings in the aspect of the proliferative effect (groups: 2,3 , and 9) were included in the wound healing assay. The results of the wound healing analysis of four groups including the non-irradiated control group on human gingival fibroblast monolayers are shown in Figure 2. The results revealed that energy densities of 4 and $6 \mathrm{~J} / \mathrm{cm}^{2}$ in groups 2 and 3 (power: $200 \mathrm{~mW}$ ) exerted a significant stimulative effect ( $P$ value: 0.010 and $<0.001$ respectively) on cell migration. In these groups, the scratched areas were significantly lower compared to the control group. Moreover, group 9 showed a positive effect on cell migration, although it was not statistically significant $(P$ value: 0.059$)$.

\section{Discussion}

In the current study, we investigated the biostimulative effect of a blue diode laser with three different powers of $200 \mathrm{~mW}$ (irradiation times of 5, 10, 15, and 20 seconds), $300 \mathrm{~mW}$ (irradiation times of 5, 10, and 15 seconds), and $400 \mathrm{~mW}$ (irradiation times of 5 and 10 seconds) on

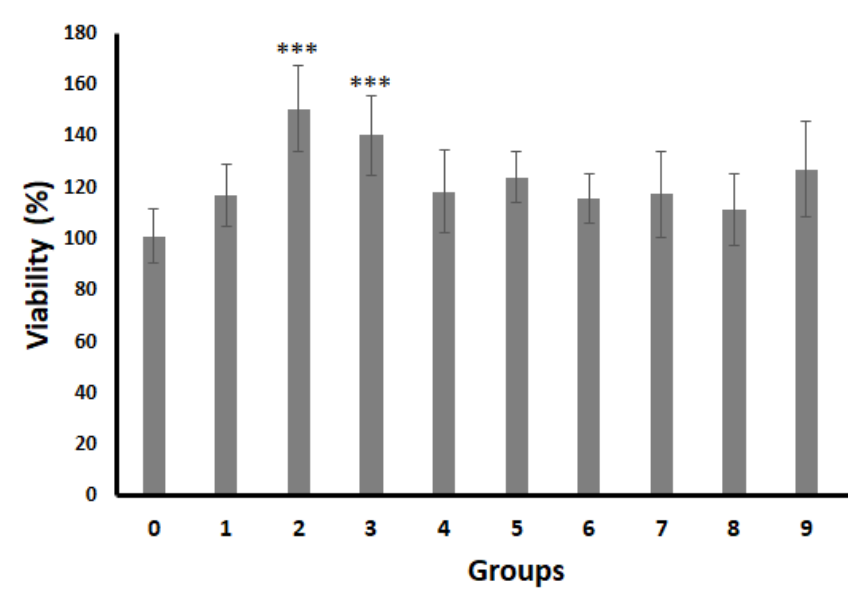

Figure 1. Results of Laser Irradiation on Cell Viability. ${ }^{* * *}$ : Corresponding to a $P$ value $\leq 0.001$ compared to control. 

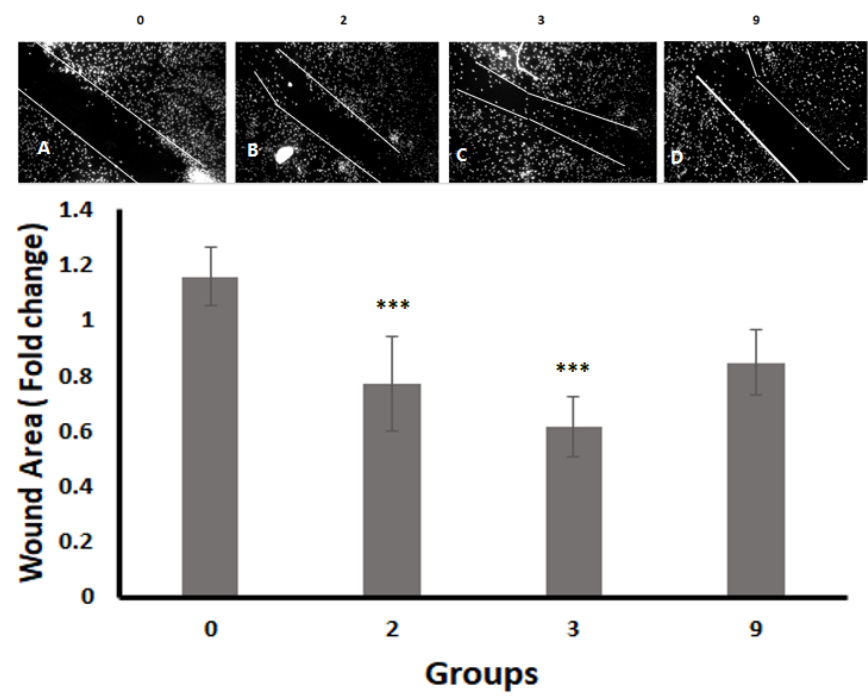

Figure 2. Results of Wound Healing Assay in Groups of Study. Figures above illustrate the areas of the scratched wound in (A) control, (B) group 2, (C) group 3, and (D) group 9. ${ }^{* * *}$ Corresponding to a $p$-value $\leq 0.001$ compared to control.

gingival fibroblast cells. The results revealed the positive effect of the blue diode laser on the proliferation and migration of human gingival fibroblast.

Several in vitro studies have previously evaluated the effect of PBM in the process of wound healing on different cell lines. ${ }^{11}$ Indeed, such in vitro studies are essential before designing further in vivo animal and human studies to assess the direct effect of lasers with multiple protocols on different cell types. ${ }^{12}$

Successful wound healing requires the support of multiple cell lines, including endothelial, epithelial, fibroblast, and immune cells. In this regard, fibroblasts play critical roles in tissue remodeling and healing. ${ }^{13}$

Laser dosimetry in wound healing studies varied in wavelength, power, and energy density with no definite consensus on optimal parameters. ${ }^{11,14}$ Reviewing the literature related to $\mathrm{PBM}$ revealed that red and near infra-red lasers have been the topic of most researches. ${ }^{15-17}$ Recently, by introducing the blue diode lasers in the dentistry market, attentions have been directed towards the application of high-power setting of blue lasers in oral surgeries due to its high absorption properties in hemoglobin and melanin, ${ }^{18}$ although the photobiomodulation effect is not known well.

Liebmann et al reported that blue light (450-490 $\mathrm{nm}$ ) with an energy density of $33 \mathrm{~J} / \mathrm{cm}^{2}$ inhibited the proliferation of neonatal foreskin keratinocytes and higher doses $\left(100 \mathrm{~J} / \mathrm{cm}^{2}\right)$ led to apoptosis procedure. They also declared the effect of low doses $\left(5 \mathrm{~J} / \mathrm{cm}^{2}\right)$ and higher settings ( 66 and $100 \mathrm{~J} / \mathrm{cm}^{2}$ ) of blue LED light on early and late differentiation of keratinocytes. ${ }^{19}$

Limited studies have evaluated the effect of blue light on human dermal fibroblasts. Accordingly, Opländer et al observed a significant reduction in proliferation and metabolic activity of human dermal fibroblasts following irradiation by blue-light $\left(200 \mathrm{~J} / \mathrm{cm}^{2}, 453 \mathrm{~nm}\right) .{ }^{20}$ Mignon et al showed biomodulative effect on the metabolic activity of dermal fibroblasts following a single treatment of 450 $\mathrm{nm}$ light at $2 \mathrm{~J} / \mathrm{cm}^{2}$, while higher doses $\left(30-60 \mathrm{~J} / \mathrm{cm}^{2}\right)$ induced inhibitory effects. ${ }^{21}$ On the contrary, a recently published article reported the suppressive effects of blue LED light $(463 \pm 50 \mathrm{~nm})$ at 4 and $8 \mathrm{~J} / \mathrm{cm}^{2}$ energy densities on adult mouse dermal fibroblasts. ${ }^{22}$

The current study is the first research investigating the photobiomodulation effect of the blue diode laser (445 $\mathrm{nm}$ ) on human gingival fibroblast. We examined the effect of different energy densities on the proliferation of fibroblast cells. Considering the results of previous studies, ${ }^{21}$ we selected all energy densities below $10 \mathrm{~J} / \mathrm{cm}^{2}$ with different power settings between $200-400 \mathrm{~mW}$ and energy densities between $2-8 \mathrm{~J} / \mathrm{cm}^{2}$. The results revealed that the laser irradiation at a power density of $400 \mathrm{~mW} /$ $\mathrm{cm}^{2}$ at time irradiation of 10 and 15 seconds corresponding to 4 and $6 \mathrm{~J} / \mathrm{cm}^{2}$ exerted the best statistically significant effect on cell viability and proliferation, which confirms the results of Mignon et al. ${ }^{21}$ The data obtained from the scratch-wound assay revealed that 4 and $6 \mathrm{~J} / \mathrm{cm}^{2}$ in the power of $200 \mathrm{~mW}$ had a significant stimulatory effect on cell migration, which was in contrast with MassonMeyers et al. They reported the inhibitory effect of blue light at a high setting $\left(55 \mathrm{~J} / \mathrm{cm}^{2}\right)$ on dermal fibroblast migration. On the other hand, no significant effect on cell migration was observed at lower doses $(2,5$, and $10 \mathrm{~J} /$ $\left.\mathrm{cm}^{2}\right){ }^{23}$ The controversies in the results may be attributed to the different responses of fibroblast cells in skin compared to those in oral tissue as well as different effects of blue light from the laser device compared to LED one. Our results were similar to the finding of a study by Castellano-Pellicena et al who reported the positive effect of blue light with low energy density $\left(2 \mathrm{~J} / \mathrm{cm}^{2}\right)$ on the migration of keratinocytes. ${ }^{4}$

In the current study, we investigated the biostimulative 
effect of three different powers of blue diode laser. In the power of $200 \mathrm{~mW}$, the gradual increase in the percentage of cell viability was observed from $2 \mathrm{~J} / \mathrm{cm}^{2}$ to maximum proliferative effect at $4 \mathrm{~J} / \mathrm{cm}^{2}$. In addition, 4 to $8 \mathrm{~J} / \mathrm{cm}^{2}$ showed a proliferative effect, although this increase was attenuated compared with $4 \mathrm{~J} / \mathrm{cm}^{2}$. In $300 \mathrm{~mW}$, we obtained the best results at $3 \mathrm{~J} / \mathrm{cm}^{2}$ and fewer effects were observed at 6 and $9 \mathrm{~J} / \mathrm{cm}^{2}$, although these differences were not statistically significant. In $400 \mathrm{~mW}$ power, there were no significant changes in cell proliferation with an increase of energy density from 4 to $8 \mathrm{~J} / \mathrm{cm}^{2}$. Based on the obtained results, we confirm our hypothesis regarding the photobiomodulative effect of the blue diode laser in the range of the setting examined in this study design.

This study is the first step in the investigation of the photobiomodulation effect of a blue diode laser in the oral cavity. Further in vivo studies are necessary to confirm the therapeutic effect of this wavelength in the wound healing process. We also recommend future studies on other cell lines such as osteoblast and stromal cells and exploring the underlying molecular mechanisms of such biostimulary effects. In previous studies, several immunological pathways involved in PBM with red and near infrared lasers were proposed. Increasing the expression of fibroblast growth factor, connective tissue growth factor, vascular-endothelial growth factor, transforming growth factor $\beta 1,{ }^{24}$ and altering the cytokines secretion ${ }^{25}$ are some of the suggested biologic mechanism of PBM in fibroblast cells. On the other hand, documents regarding the biological effects of blue light on fibroblasts are limited without adequate pieces of evidence; however, the role of cryptochromes and opsins in mediating cell response to visible and UV light and triggering multiple cellular signaling cascades was mentioned in one study. ${ }^{3}$

Considering the encouraging results of this study, we may benefit from the biostimulation effects of blue lasers on the process of wound healing in the oral cavity while taking the advantages of sharp cutting with high power in oral surgery.

\section{Conclusion}

Based on the limitations and findings of the current in vitro cell culture study, PBM using a $445 \mathrm{~nm}$ diode laser has a positive effect on the proliferation and migration rate of cultured human gingival fibroblast. These promoting effects might introduce a new therapeutic use of blue diode lasers in enhancing the wound healing processes in the oral cavity.

\section{Conflict of interests}

The authors declare no conflict of interest.

\section{Ethical Considerations}

Human gingival fibroblast cells with Accession Cell No: IBRC C10459 were obtained from the Iranian Biological
Resource Center not harvested directly from human subject.

\section{Acknowledgment}

This research did not receive any specific grant from funding agencies in the public, commercial, or not-forprofit sectors.

\section{References}

1. Dionysopoulos D, Tolidis K, Strakas D, Gerasimou P, Sfeikos T, Gutknecht N. Effect of radiant heat on conventional glass ionomer cements during setting by using a blue light diode laser system (445 nm). Lasers Med Sci. 2017;32(3):703-9. doi: 10.1007/s10103-017-2178-x.

2. Fornaini C, Merigo E, Rocca JP, Lagori G, Raybaud H, Selleri $\mathrm{S}$, et al. $450 \mathrm{~nm}$ blue laser and oral surgery: Preliminary ex vivo study. J Contemp Dent Pract. 2016;17(10):795-800. doi: 10.5005/jp-journals-10024-1933.

3. Mignon C, Uzunbajakava NE, Castellano-Pellicena I, Botchkareva NV, Tobin DJ. Differential response of human dermal fibroblast subpopulations to visible and near-infrared light: Potential of photobiomodulation for addressing cutaneous conditions. Lasers Surg Med. 2018;50(8):859-82. doi: 10.1002/lsm.22823.

4. Castellano-Pellicena I, Uzunbajakava NE, Mignon C, Raafs B, Botchkarev VA, Thornton MJ. Does blue light restore human epidermal barrier function via activation of Opsin during cutaneous wound healing? Lasers Surg Med. 2019;51(4):370-382. doi: 10.1002/lsm.23015.

5. Wang Y, Huang YY, Wang Y, Lyu P, Hamblin MR. Photobiomodulation (blue and green light) encourages osteoblastic-differentiation of human adipose-derived stem cells: role of intracellular calcium and light-gated ion channels. Sci Rep. 2016;6:33719. doi: 10.1038/srep33719.

6. deFreitasLF,Hamblin MR.Proposed ofphotobiomodulation or low-level light therapy. IEEE J Sel Top Quantum Electron. 2016;22(3). doi: 10.1109/jstqe.2016.2561201.

7. Solmaz H, Ulgen Y, Gulsoy M. Photobiomodulation of wound healing via visible and infrared laser irradiation. Lasers Med Sci. 2017;32(4):903-10. doi: 10.1007/s10103017-2191-0.

8. Bainbridge P. Wound healing and the role of fibroblasts. J Wound Care. 2013;22(8):407-8, 410-12. doi: 10.12968/ jowc.2013.22.8.407.

9. Kumar P, Nagarajan A, Uchil PD. Analysis of cell viability by the MTT assay. Cold Spring Harb Protoc. 2018;2018 (6). doi: $10.1101 /$ pdb.prot095505.

10. Kramer N, Walzl A, Unger C, Rosner M, Krupitza G, Hengstschläger $\mathrm{M}$, et al. In vitro cell migration and invasion assays. Mutat Res. 2013;752(1):10-24. doi: 10.1016/j. mrrev.2012.08.001.

11. Kuffler DP. Photobiomodulation in promoting wound healing: a review. Regen Med. 2016;11(1):107-22. doi: 10.2217/rme.15.82.

12. Ren C, McGrath C, Jin L, Zhang C, Yang Y. Effect of diode low-level lasers on fibroblasts derived from human periodontal tissue: a systematic review of in vitro studies. Lasers Med Sci. 2016;31(7):1493-510. doi: 10.1007/s10103016-2026-4. 
13. Weinreb $M$, Nemcovsky CE. In vitro models for evaluation of periodontal wound healing/regeneration. Periodontol 2000. 2015;68(1):41-54. doi: 10.1111/prd.12079.

14. França CM, Anders JJ, Lanzafame RJ. Photobiomodulation in wound healing: What are we not considering? Photomed Laser Surg. 2016;34(2):51-2. doi: 10.1089/pho.2015.4073.

15. Heidari M, Paknejad M, Jamali R, Nokhbatolfoghahaei H, Fekrazad R, Moslemi N. Effect of laser photobiomodulation on wound healing and postoperative pain following free gingival graft: A split-mouth triple-blind randomized controlled clinical trial. J Photochem Photobiol B. 2017;172:109-14. doi: 10.1016/j.jphotobiol.2017.05.022.

16. Arany PR. Craniofacial wound healing with photobiomodulation therapy: New insights and current challenges. J Dent Res. 2016;95(9):977-84. doi: $10.1177 / 0022034516648939$.

17. Yadav A, Gupta A. Noninvasive red and near-infrared wavelength-induced photobiomodulation: promoting impaired cutaneous wound healing. Photodermatol Photoimmunol Photomed. 2017;33(1):4-13. doi: 10.1111/ phpp.12282.

18. Reichelt J, Winter J, Meister J, Frentzen M, Kraus D. A novel blue light laser system for surgical applications in dentistry: evaluation of specific laser-tissue interactions in monolayer cultures. Clin Oral Investig. 2017;21(4):985-94. doi: 10.1007/s00784-016-1864-6.

19. Liebmann J, Born M, Kolb-Bachofen V. Blue-light irradiation regulates proliferation and differentiation in human skin cells. J Invest Dermatol. 2010;130(1):259-69. doi: 10.1038/jid.2009.194.
20. Opländer C, Deck A, Volkmar CM, Kirsch M, Liebmann J, Born M, et al. Mechanism and biological relevance of bluelight (420-453 nm)-induced nonenzymatic nitric oxide generation from photolabile nitric oxide derivates in human skin in vitro and in vivo. Free Radic Biol Med. 2013;65:136377. doi: 10.1016/j.freeradbiomed.2013.09.022.

21. Mignon C, Uzunbajakava NE, Raafs B, Botchkareva NV, Tobin DJ. Photobiomodulation of human dermal fibroblasts in vitro: decisive role of cell culture conditions and treatment protocols on experimental outcome. Sci Rep. 2017;7(1):2797. doi: 10.1038/s41598-017-02802-0.

22. Chang LY, Fan SMY, Liao YC, Wang WH, Chen YJ, Lin SJ. Proteomic analysis reveals anti-fibrotic effects of blue light photobiomodulation on fibroblasts. Lasers Surg Med. 2019;52(4):358-72. doi: 10.1002/lsm.23137.

23. Masson-Meyers DS, Bumah VV, Enwemeka CS. A comparison of four methods for determining viability in human dermal fibroblasts irradiated with blue light. $J$ Pharmacol Toxicol Methods. 2016;79:15-22. doi: 10.1016/j. vascn.2016.01.001.

24. Illescas-Montes R, Melguizo-Rodríguez L, García-Martínez O, de Luna-Bertos E, Manzano-Moreno FJ, Ruiz C, et al. Human fibroblast gene expression modulation using 940 NM diode laser. Sci Rep. 2019;9(1):12037. doi: 10.1038/ s41598-019-48595-2.

25. Harorli OT, Hatipoglu M, Erin N. Effect of photobiomodulation on secretion of IL-6 and IL-8 by human gingival fibroblasts in vitro. Photobiomodul Photomed Laser Surg. 2019;37(8):457-464. doi: 10.1089/ photob.2018.4589. 